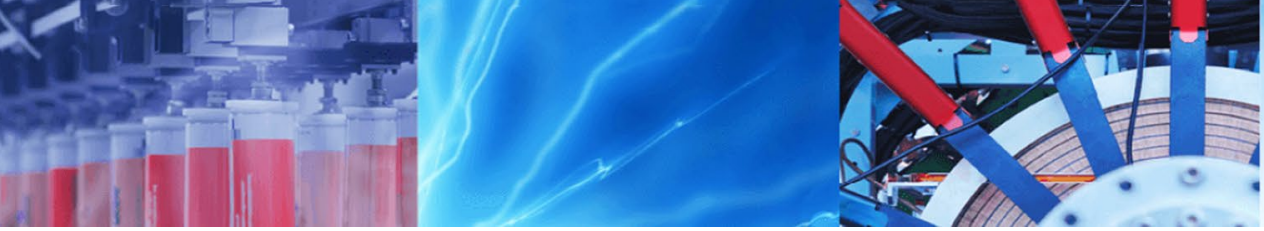

Research Article

\title{
Green synthesis of Zinc oxide nanoparticles (ZnO NPs) and their biological activity
}

\author{
Mahesh Midatharahalli Chikkanna ${ }^{1} \cdot$ Shivayogeeswar E. Neelagund ${ }^{1} \cdot$ Kotresh K. Rajashekarappa ${ }^{1}$
}

C The Author(s) 2018 OPEN

\begin{abstract}
Zinc oxide $(\mathrm{ZnO})$ has broad applications in various areas. Green synthesis is an alternative to conventional physical and chemical methods. Green synthesis of nanoparticles is gaining importance due to its cost-effectiveness, reduction of toxic chemicals and extensive antimicrobial activity. Herein, we have discovered synthesis of zinc oxide nanoparticles (ZnONPs) using agro waste materials like sheep and goat faecal matter as a reducing agent. Synthesized ZnONPs were evaluated for their purity, particle size, morphological structure, using UV-visible spectroscopy, Fourier transforms infrared spectroscopy, X-ray diffraction and scanning electron microscope analysis. However, nanoparticles gain low crystallite size, they seemed to be uneven structures like spongy like and flower shaped particles. Obtained nanoparticles exhibit good antimicrobial activity and minimum inhibitory concentration against Salmonella typhimurium and Bacillus subtilis. Agro-waste based green synthesized ZnONPs possess small sized particles, enhances the good antimicrobial effect. This research leads to develop a new way of cost-effective synthesis and reducing usage of chemicals in further studies.
\end{abstract}

Keywords Zinc oxide nanoparticles (ZnONPs) · Goat and sheep faecal matter · Green synthesis · Antimicrobial activity · Minimum inhibitory concentration

\section{Introduction}

The "green chemistry" which involves using eco-friendly materials and ensures compatibility for pharmaceutical and other biomedical applications, where toxic chemicals are not used for the synthesis process. The biological approach which includes different types of microorganisms has been used to synthesize different metallic NPs, which has advantages over other chemical methods as this is greener, energy saving and cost-effective. The biocompatibility of bio-inspired NPs offers very interesting applications in biomedicine and related fields [1]. The coating of biological molecules on the surface of NPs makes them biocompatible in comparison with the NPs prepared by chemical methods [2-4]. The use of agricultural wastes [5] or plants and their parts $[6,7]$ has emerged as an alternative to chemical synthetic procedures because it does not require elaborate processes such as intracellular synthesis and multiple purification steps or the maintenance of microbial cell cultures [8]. Phytochemical studies indicate that the plant and plant metabolites contain important phytochemicals such as lupeol, ursolic acid, oleanolic acid, sitosterol, rutin, leucocyanidin, anthocyanins, proanthocyanidins, glycosides of kaempferol and quercetin. Pharmacological studies suggest that the plant possesses anti-oxidative, antibacterial, gastro protective, hepatoprotective, anti-diarrheal, anti-nociceptive, anti-mutagenic, anti-eoplastic and chemo preventive effects [9].

\section{Electronic supplementary material The online version of this article (https://doi.org/10.1007/s42452-018-0095-7) contains} supplementary material, which is available to authorized users.

Shivayogeeswar E. Neelagund, neelgund@kuvempu.ac.in; Mahesh Midatharahalli Chikkanna, maheshgowda.mc@gmail.com; Kotresh K. Rajashekarappa, kotresh59@gmail.com | 'Department of Studies and Research in Biochemistry, Jnana Sahyadri, Kuvempu University, Shankaraghatta, Shimoga, Karnataka 577 451, India. 
Among the metal oxide nanoparticles, zinc oxide nanoparticles have drawn the attention of many researchers for their unique optical and chemical behaviours which can be easily tuned by changing the morphology. Zinc oxide nanoparticles (ZnONPs) belongs to the class of metal oxides, which is characterized by photocatalytic and photo-oxidizing capacity against chemical and biological species [10]. Within the large family of metal oxide nanoparticles, zinc oxide nanoparticles have been used in various cutting-edge applications like electronics, communication, sensor, cosmetics, environmental protection, biology and medicinal industry [11-15]. Moreover, zinc oxide nanoparticles have a tremendous potential in biological applications like biological sensing, biological labelling, gene delivery, drug delivery and nanomedicines. Durable nanoparticles were also synthesized using cotton fabrics [16].

Since various attempts have been made in the field of nanoparticle synthesis by different methods, biological synthesis is the new and advanced method due to its low cost, less usage of chemicals, and results in more yield. Various researchers studied the biosynthesis of zinc oxide nanoparticles using fungal cultures [17-19] and date seed extract [20]. In present study, we have used sheep and goat faecal matter as reducing agents, they consume plants and their constituents, so their excrete contains secondary metabolites such as plant residues, alkaloids, terpenoids, flavonoids, phenols, nitrogen excretions etc., which mainly act as reducing agents in nanoparticle synthesis, so that we have chosen goat and sheep faecal matter as reducing agents.

\section{Experimental}

\subsection{Materials and methods}

All materials and chemicals were used as received. Zinc sulfate (M.W 287.54) was purchased from Jain chemicals, Shimoga, Karnataka, India. Faecal matter was collected from a local area of Madhugiri, which were collected, washed with distilled water, shade dried at room temperature and kept in sealed cover for further use.

\subsection{Extract preparation}

$20 \mathrm{~g}$ of the dried faecal matter was taken in a different container, crushed in pestle mortar for powder and mix with $100 \mathrm{ml}$ of distilled water. Mix thoroughly and kept microwave heat for 3 times for 3 min under a power of 90 W. After cooling, filtered with Whatman filter paper No.
1 , the filtrates were used as reducing agent for nanoparticle synthesis.

\subsection{Green synthesis of zinc oxide nanoparticles}

$10 \mathrm{ml}$ of goat and sheep faecal matter extracts were added to 2 different conical flasks containing $100 \mathrm{ml}$ of $0.1 \mathrm{M}$ Zinc sulfate ( $\mathrm{ZnSO} 4)$ solution. $\mathrm{pH}$ of the solution was maintained to 8 to attain smaller size particles. The solutions were kept on a magnetic stirrer at room temperature for $24 \mathrm{~h}$ and kept for $1-2 \mathrm{~h}$ without disturbing, the solution turns into milky white indicates the particles formation. The solution was centrifuged at $10,000 \mathrm{rpm}$ for $10 \mathrm{~min}$, then the supernatant was discarded and pellets were collected. Pellets were washed with distilled water for 6-8 times to remove solid faecal matter impurities along with polar and non-polar solvents to remove secondary metabolites and other organic impurities. Washed samples dried in an oven at $100^{\circ} \mathrm{C}$ to remove other impurities, and particles were subjected to calcination at $350-400{ }^{\circ} \mathrm{C}$ which converts zinc nanoparticles to zinc oxide nanoparticles, calcination also leads to increase slightly in the particles size. The resulting dried sample was crushed into powder and stored in airtight container for further analysis.

In our investigation we have synthesized nanoparticles by using agro waste as reducing agents, they contain secondary metabolites which came along with green parts of plants, which were consumed by goat and sheep. These secondary metabolites act as reducing agents in the synthesis process.

\subsection{Synthesized ZnONPs characterization}

Synthesized nanoparticles were characterized for further confirmation. The absorption spectrum was measured by using UV-visible spectrophotometer (HR 4000 UV-Vis spectrophotometer, UV-Vis-NIR light source, DT-MINI2-GS, Jaz detector). The average particle size and phase detection of particles were evaluated by $\mathrm{X}$-ray diffraction (XRD) pattern using X'pert Pro diffractometer (Phillips, $\mathrm{Cu}$-Ka radiation, $\lambda \mathrm{Cu}=1.5148 \AA$ ) working at $30 \mathrm{~mA}$ and $40 \mathrm{kV}$ recorded in the $2 \theta$ range between $10^{\circ}$ and $90^{\circ}$ (scan rate $1^{\circ} \mathrm{min}^{-1}$ ). Morphological features were studied using a Philips XL30 scanning electron microscope (SEM).

\subsection{Antibacterial activity and MIC}

Bacterial strains of gram-positive Bacillus subtilis ATCC 19659 and gram-negative Salmonella typhimurium ATCC 23564 were used to determine antibacterial activity by agar well diffusion method. Nutrient agar medium was 
used as a culture, $100 \mu \mathrm{l}$ of $24 \mathrm{~h}$ old mature cultures were swabbed using the L-shaped rod on medium. Wells were made using sterile cork borer $(6 \mathrm{~mm})$. ZnONPs were dispersed with dimethyl sulfoxide (DMSO $\left(\mathrm{CH}_{3}\right)_{2} \mathrm{SO}$, m.m $78.13 \mathrm{~g} / \mathrm{mol}$.) for good dispersion of nanoparticles, which was used as a control. Ampicillin $\left(\mathrm{C}_{16} \mathrm{H}_{19} \mathrm{~N}_{3} \mathrm{O}_{4} \mathrm{~S}\right.$, m.w. $349.41 \mathrm{~g} / \mathrm{mol}$.) was used as a standard. Zone of inhibition (ZOI) was measured in $\mathrm{mm}$. Four wells were made in each Petri plate and were filled with $50 \mu \mathrm{l}$ of DMSO, ampicillin $(100 \mu \mathrm{g} / \mathrm{ml}), \mathrm{ZnONPs}(\mathrm{GFM})(100 \mu \mathrm{g} / \mathrm{ml})$ and ZnONPs (SFM) $(100 \mu \mathrm{g} / \mathrm{ml})$ respectively, GFM and SFM extracts were tested in different plates against both organisms.

Minimum inhibitory concentration (MIC) was measured against Bacillus subtilis ATCC 19659 and gram-negative Salmonella typhimurium ATCC 23564. Four wells were made in each Petri plate and each well were filled with different concentrations of DMSO $(50 \mu \mathrm{l})$, ampicillin $(100 \mu \mathrm{g} /$ $\mathrm{ml})$, nanoparticles synthesized using goat and sheep faecal matter (NPs GFM and SFM) $(100 \mu \mathrm{g} / \mathrm{ml})$ and goat and sheep faecal matter solutions $(50 \mu \mathrm{l})$. The plates were left for $24 \mathrm{~h}$ to grow the organisms and inhibition zones were measured in $\mathrm{mm}$ and recorded.

\section{Results and discussion}

\subsection{UV-visible spectrophotometer analysis}

Synthesized nanoparticles were subjected to UV-visible spectrophotometer analysis which confirms the formation of particles in the initial stage. The solid white coloured samples of ZnONPs synthesized using both sheep and goat faecal matters were subjected to scan UV-Spectrophotometer in the range of 200-1000 nm. Various peaks were observed under UV region, peaks at $217.45 \mathrm{~nm}, 298.57 \mathrm{~nm}, 304.64 \mathrm{~nm}, 312.66 \mathrm{~nm}, 316.07 \mathrm{~nm}$, $324.23 \mathrm{~nm}, 335.96 \mathrm{~nm}, 339.88 \mathrm{~nm}, 346.08 \mathrm{~nm}, 352.60 \mathrm{~nm}$ and $353.57 \mathrm{~nm}$ for nanoparticles synthesized using goat fecal matter as reducing agent, peaks at $213.87 \mathrm{~nm}$, $224.75 \mathrm{~nm}, 232.58 \mathrm{~nm}, 298.28 \mathrm{~nm}, 304.82 \mathrm{~nm}, 311.33 \mathrm{~nm}$, $316.98 \mathrm{~nm}, 323.97 \mathrm{~nm}, 335.25 \mathrm{~nm}, 337.45 \mathrm{~nm}, 339.62 \mathrm{~nm}$, $351.38 \mathrm{~nm}, 352.67 \mathrm{~nm}$ and $356.60 \mathrm{~nm}$ for nanoparticles synthesized using sheep fecal matter as reducing agent indicates the zinc oxide nanoparticles formation. Peaks at $352.67 \mathrm{~nm}$ and $356.60 \mathrm{~nm}$ indicate the zinc oxide nanoparticles formation using goat faecal matter and peaks from $352.60 \mathrm{~nm}$ and $353.67 \mathrm{~nm}$ [21] indicates the zinc oxide nanoparticles formation using sheep faecal matter as reducing agent (Fig. 1).

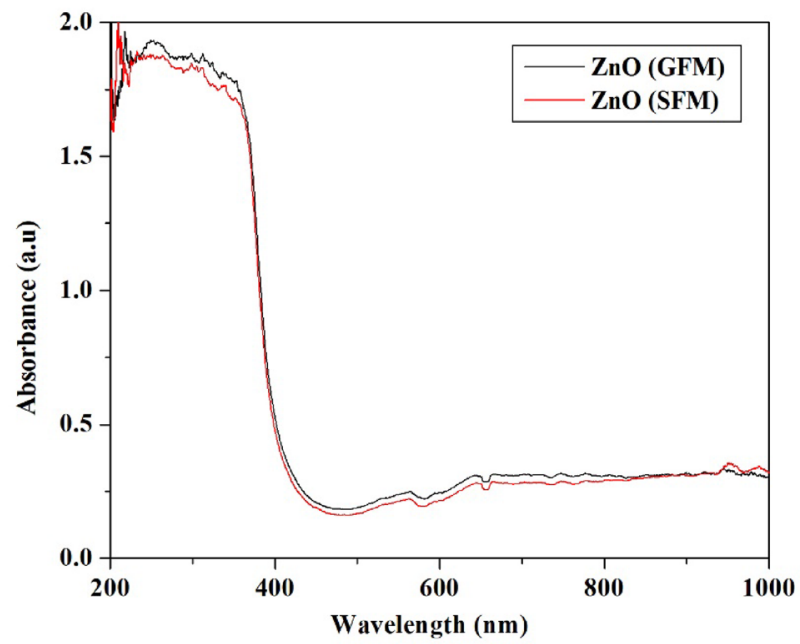

Fig. 1 UV-visible absorption spectrum of zinc oxide nanoparticles synthesized using goat and sheep faecal matter

\subsection{XRD analysis}

Synthesized particles were subjected to X-Ray diffraction studies, to obtain the crystallinity and average particle size of synthesized nanoparticles. Following figures reveal the XRD pattern of zinc oxide nanoparticles. Number of Bragg reflections for $\mathrm{ZnONPs}$ using goat fecal matter appears at $2 \theta=31.77^{\circ}(100), 34.44^{\circ}(002), 36.27^{\circ}(101), 47.62^{\circ}(102)$, $56.73^{\circ}(110), 62.96^{\circ}(103), 68.06^{\circ}(112), 69.13^{\circ}(201)$ and 77.04 (202). Peaks for ZnONPs synthesized using sheep fecal matter appears at $2 \theta=31.79^{\circ}(100), 34.47^{\circ}(002)$, $36.26^{\circ}(101), 47.67^{\circ}(102), 56.66^{\circ}(110), 62.94^{\circ}(103)$, $68.01^{\circ}(112), 69.19^{\circ}(201)$ and $77.04^{\circ}(202)$ respectively. The planes show a good agreement with the JCPDS file (JCPDS: 80-0075 card ICSD\#: 067849), which elucidates the hexagonal wurtzite structure which corresponds to pure zinc oxide nanoparticles [22, 23]. By using Debey-Scherrer equation [24], the average particle size of synthesized particles was calculated to be as $28.5 \mathrm{~nm}$ for ZnONPs (GFM) and $24.4 \mathrm{~nm}$ for ZnONPs (SFM). The broad peaks indicate the decreasing in crystallinity, which inwards suggests the formation of smaller particles size (Fig. 2).

\subsection{FTIR analysis}

The Fourier transform infrared spectra (FTIR) were analyzed using FTIR JASCO FTIR-5300 model, in the range of $0-4000 \mathrm{~cm}^{-1}$ was recorded using $\mathrm{KBr}$ pellet method to recognize the organic, inorganic, biomolecule residues along with nanoparticle formation, which may come along via reducing agent on to the surface of ZnONPs. Absorption bands for ZnONPs (GFM) at $464.51 \mathrm{~cm}^{-1}, 537.92 \mathrm{~cm}^{-1}$, $672.03 \mathrm{~cm}^{-1}, 2334.10 \mathrm{~cm}^{-1}, 2361.74 \mathrm{~cm}^{-1}, 3445.55 \mathrm{~cm}^{-1}$. 


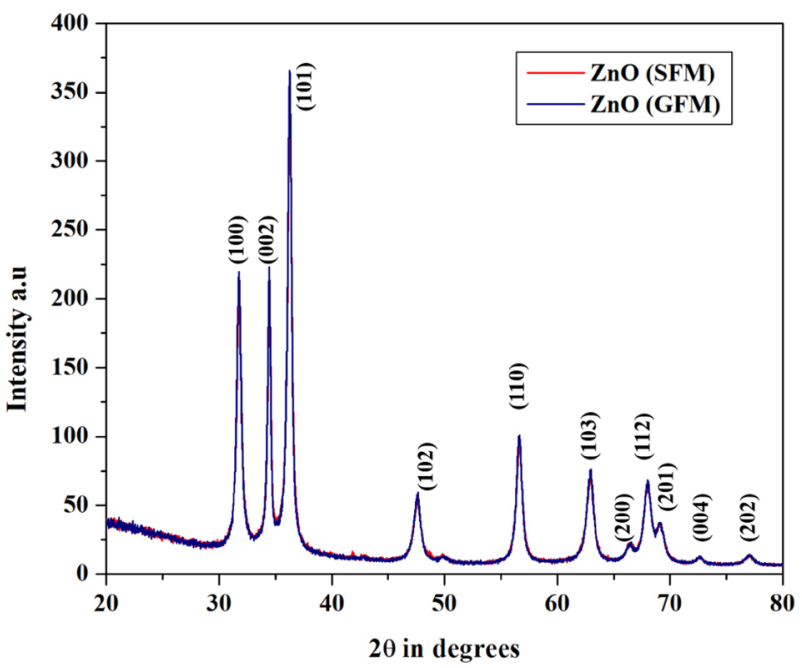

Fig. 2 XRD pattern of zinc oxide nanoparticles synthesized using goat and sheep faecal matter

The bands for ZnONPs (SFM) at $433.79 \mathrm{~cm}^{-1}, 461.27 \mathrm{~cm}^{-1}$, $498.51 \mathrm{~cm}^{-1}, 937.71 \mathrm{~cm}^{-1}, 1099.15 \mathrm{~cm}^{-1}, 1630.06 \mathrm{~cm}^{-1}$, $2340.96 \mathrm{~cm}^{-1}, 3417.63 \mathrm{~cm}^{-1}$. The intense broad bands at $3445.55 \mathrm{~cm}^{-1}$ and $3417.63 \mathrm{~cm}^{-1}$ were assigned to $\mathrm{O}-\mathrm{H}$ stretching of flavonoids, polyphenols and $\mathrm{C}-\mathrm{O}$ groups on the surface of $\mathrm{ZnO}$ crystal nanostructure which may present in faecal matter extract that indicates the bending frequencies of $\mathrm{H}_{2} \mathrm{O}$ reveals the water content on the surface of nanoparticles [25]. The intense peaks at $2334.10 \mathrm{~cm}^{-1}$, $2361.74 \mathrm{~cm}^{-1}$, and $2340.96 \mathrm{~cm}^{-1}$ indicate the formation of $\mathrm{CO}_{2}$ molecules which may absorb during synthesis [26]. The peak at $1630.06 \mathrm{~cm}^{-1}$ is corresponding to $C=C$ stretch in the aromatic ring. Bands at $1099.15 \mathrm{~cm}^{-1}$ and $937.71 \mathrm{~cm}^{-1}$ indicates the stretching of $\mathrm{C}-\mathrm{O}$ in the amino acid [27]. Bulk peaks at $672.03 \mathrm{~cm}^{-1}, 537.92 \mathrm{~cm}^{-1}$ and $498.51 \mathrm{~cm}^{-1}$ indicates the significance presence of $\mathrm{Si}-\mathrm{O}$ bending vibration which may be the possible inclusion with fecal matter residues [28], peaks at $464.51 \mathrm{~cm}^{-1}$ for ZnO-GFM and peaks at $433.79 \mathrm{~cm}^{-1}$ and $461.27 \mathrm{~cm}^{-1}$ for $\mathrm{ZnO}$-SFM indicates the stretching vibrations of zinc and oxygen bonds, which shows the formation of $\mathrm{ZnO}$ nanoparticles [29-31].

Regardless of repeated washing, the surveillance proves the subsistence of aldehydes, amines, terpenoids and phenolic compounds were bounded to the surface of ZnONP's enhances the stabilization by covering the metallic nanoparticles [32]. Synthesized ZnONP's were surrounded by proteins and metabolites such as terpenoids, flavonoids, aldehydes, ketones as functional groups. From FTIR analysis we conclude that the carbonyl groups from the amino acid residues and proteins have the stronger ability to bind metal showing that the proteins can prevent agglomeration. This indicates that in an aqueous medium

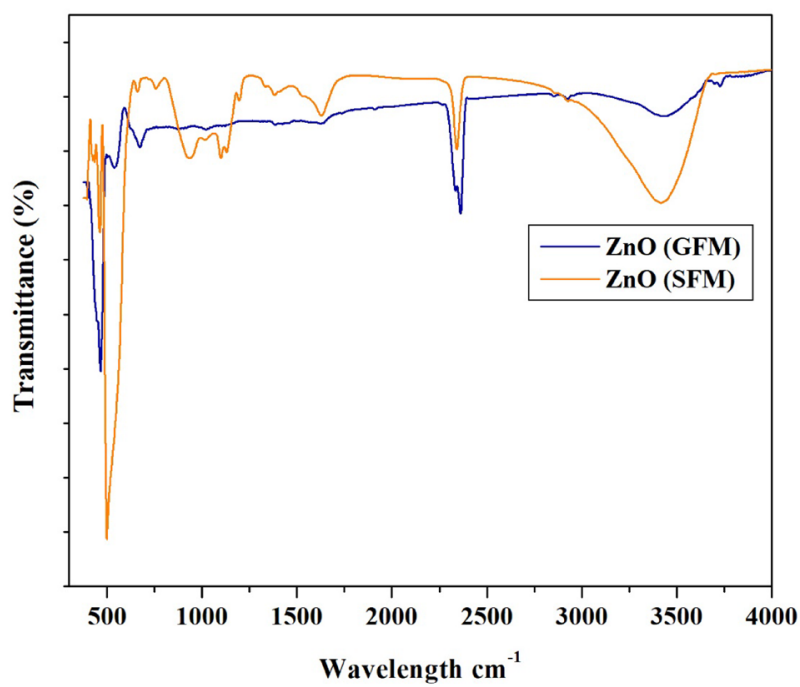

Fig. 3 FTIR spectra of zinc oxide nanoparticles synthesized using goat faecal matter and sheep faecal matter

the biological molecules could possibly perform dual functions of formation and stabilization of ZnONP's. Secondary metabolites such as flavonoids or terpenoids conjugate with nanoparticles adsorb on the nanoparticles surface may possibly by interaction through carbonyl groups or $\pi$-electrons in the absence of other strong ligating agents in sufficient concentration. The presence of reducing sugars in the solution could be responsible for the reduction of metal ions and the formation of the zinc oxide nanoparticles. It is also possible that the terpenoids play a role in the reduction of metal ions by oxidation of aldehydic groups in the molecules to carboxylic acids (Fig. 3).

\subsection{Scanning electron microscope (SEM) and energy dispersive spectra (EDS) analysis}

SEM analysis is used to analyze the structural and morphological confirmation of synthesized nanoparticles Fig. $4 a$, b reveals the SEM images of ZnONPs (GFM) and ZnONPs (SFM). Particles clearly execute the spherical structural formation. In following images we can clearly observe the obtained particles possess nearly spongy like and flower-like structural nanoparticles. Following figures, clearly observe oval like structured particles and flowerlike structured irregularly formed particles. Nanoparticles exhibits lower particle size and possess nearly 40-120 nm for ZnONPs (GFM) and 60-130 nm for ZnONPs (SFM). A homogenous distribution of particles can give us better knowledge on a morphological study and approximate particles size.

From the literature survey [33] it was found that usage of natural particles as reducing agents sometimes leads to particles agglomeration and somewhat particles will seem 

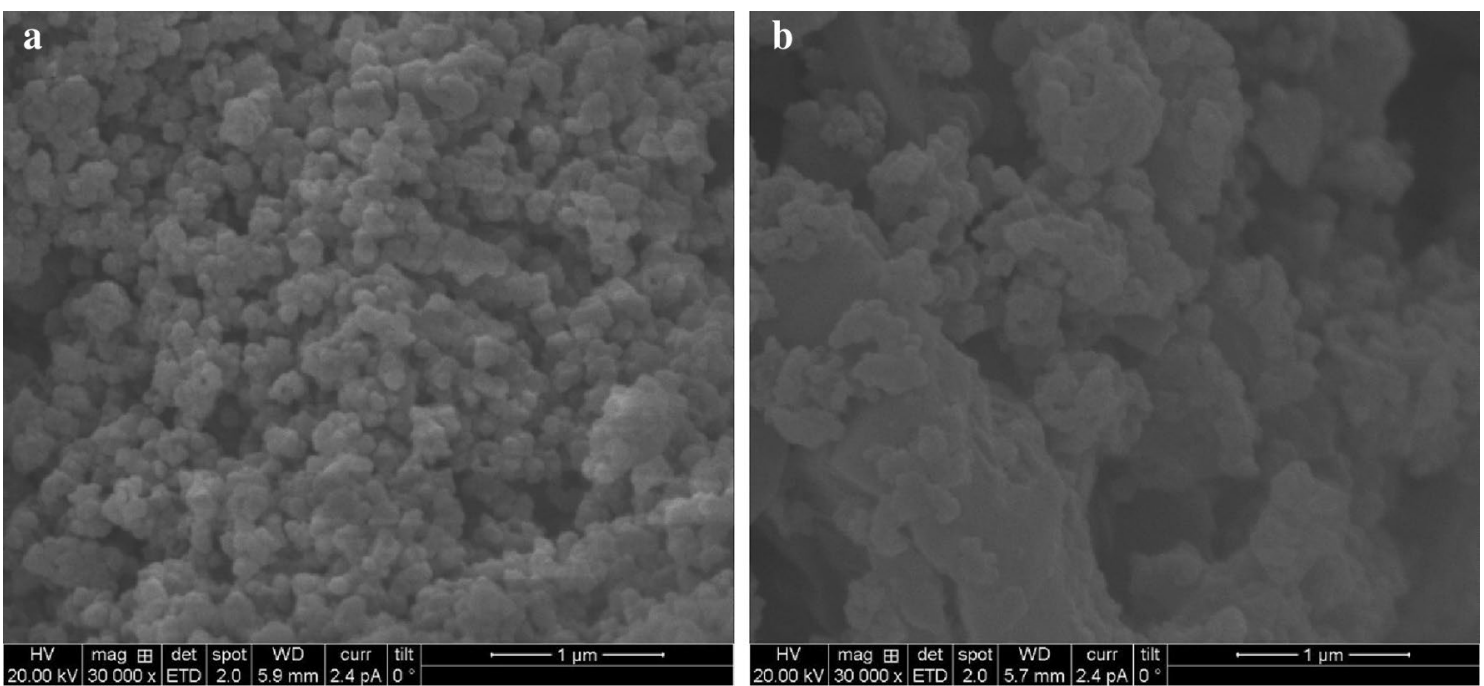

Fig. 4 SEM images of Zinc oxide nanoparticles synthesized using goat feacal matter (a) sheep feacal matter (b)

a

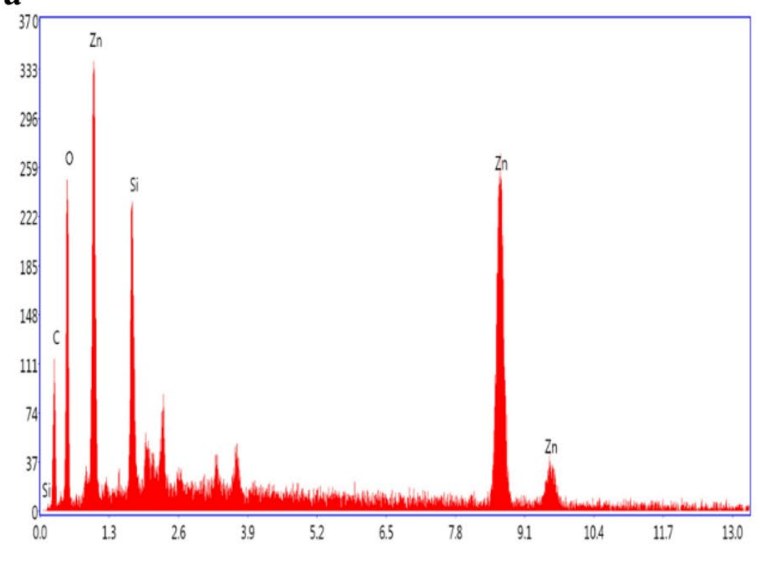

b

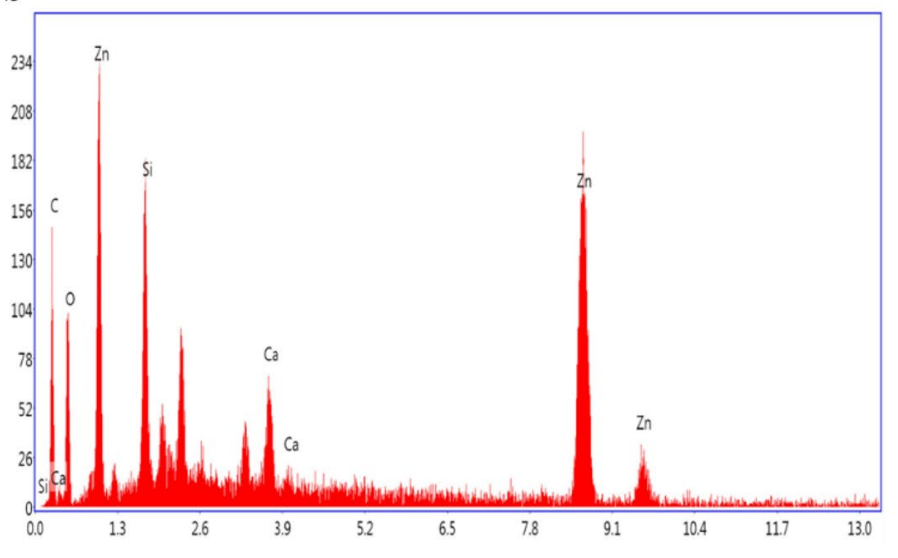

Leec: 30.00 Cnts 0.000 keV Det: Octane Pro Det

Fig. 5 EDS pattern of Zinc oxide nanoparticles synthesized using goat feacal matter (a) sheep feacal matter (b)

Table 1 EDS analysis of zinc oxide nanoparticles synthesized using goat feacal matter

Table 2 EDS analysis of zinc oxide nanoparticles synthesized using sheep feacal matter

\begin{tabular}{lcclllllll}
\hline Element & Weight \% & Atomic \% & Net Int. & Error \% & K ratio & Z & R & A & F \\
\hline C K & 26.27 & 55.66 & 17.47 & 15.31 & 0.0517 & 1.1845 & 0.8878 & 0.1663 & 1.0000 \\
O K & 10.10 & 16.06 & 17.95 & 15.05 & 0.0225 & 1.1387 & 0.9121 & 0.1956 & 1.0000 \\
Si K & 5.39 & 4.89 & 37.89 & 11.42 & 0.0266 & 1.0444 & 0.9673 & 0.4704 & 1.0048 \\
Ca K & 2.90 & 1.84 & 20.28 & 15.41 & 0.0277 & 0.9919 & 1.0083 & 0.9184 & 1.0505 \\
Zn K & 55.35 & 21.55 & 96.51 & 4.70 & 0.4995 & 0.8529 & 1.0463 & 1.0061 & 1.0522 \\
\hline
\end{tabular}

\begin{tabular}{lccccccccc}
\hline Element & Weight \% & Atomic \% & Net Int. & Error \% & K ratio & Z & R & A & F \\
\hline C K & 21.20 & 46.46 & 18.04 & 14.83 & 0.0400 & 1.1917 & 0.8851 & 0.1583 & 1.0000 \\
O K & 15.04 & 24.74 & 42.21 & 11.94 & 0.0396 & 1.1457 & 0.9094 & 0.2296 & 1.0000 \\
Si K & 5.84 & 5.48 & 53.62 & 10.74 & 0.0282 & 1.0510 & 0.9649 & 0.4570 & 1.0045 \\
Zn K & 57.92 & 23.32 & 135.92 & 4.21 & 0.5266 & 0.8587 & 1.0450 & 1.0069 & 1.0515 \\
\hline
\end{tabular}


to have a bit bigger particles size, correspondence to $\mathrm{ZnO}$ nanoparticles by biological synthesis [34].

EDS pattern of zinc oxide nanoparticles was shown in Fig. 5a, $b$ and percentage analysis were showed in Tables 1 and 2. From these figures and tables, we can observe the peaks of zinc and oxygen along with some other constituents as Sulphur, carbon, silicon and calcium which may come along with a faecal matter which sometimes acted as a capping agent to nanoparticles.

When we observe the table we can clearly notice the major element as zinc which comprises more than $50 \%$ of total constituent along with oxygen, which clearly confirms the formation of pure zinc oxide nanoparticles. This indicates the nanoparticles synthesis can be made easily by biological synthesis method.

\subsection{ZOI and MIC of ZnONPs}

Synthesized nanoparticles were subjected to antimicrobial activity. Particles were tested against both gram-positive Bacillus Subtilis ATCC 19659 and gram-negative Salmonella Typhimurium ATCC 23564 using agar well plate method [35]. Secondary cultures were made using primary culture and $24 \mathrm{~h}$ old secondary cultures were used for the activity. No zone of inhibition (ZOI) was observed for DMSO for both organisms.

Radial diameter of ZOI against S. Typhi was found to be $3.23 \pm 0.15 \mathrm{~mm}$ for ZnONPs (GFM), $2.93 \pm 0.15 \mathrm{~mm}$ for ZnONPs (SFM) and $4.43 \pm 0.05 \mathrm{~mm}$ for ampicillin. ZOI against $B$. subtilis was found to be as $2.46 \pm 0.06 \mathrm{~mm}$ for ZnONPs (GFM), $2.1 \pm 0.10 \mathrm{~mm}$ for ZnONPs (SFM) and $3.16 \pm 0.05 \mathrm{~mm}$ for ampicillin. It shows significantly an average ZOI for ZnONPs against both organisms when compared with standard ampicillin. Based on these results, it could be concluded that these synthesized ZnONPs has shown significant antibacterial activity on both of the gram classes of bacteria. This antibacterial activity may be attributed due to the presence of amines and carboxyl groups on their cell surface and occurrence of greater affinity of zinc oxide ions toward these groups [36]. ZnONPs has shown efficient antibacterial property due to their extremely large surface area, which could provide better contact with microorganisms. Zinc ions released subsequently may be bind to DNA molecules and lead to disorder of the helical structure by cross-linking within and between the nucleic acid strands. Zinc ions inside bacterial cells were also involved in the disruption of biochemical processes $[37,38]$. The antibacterial activity of ZnONPs towards Gram-negative bacteria was observed higher when compared to Gram-positive bacteria. The difference in activity between these two types of bacteria could be attributed to the structural and compositional differences in the cell membrane [39]. Gram-positive bacteria have thicker peptidoglycan cell membranes compared to the Gram-negative bacteria and it is harder for ZnONPs to penetrate it, resulting in a low antibacterial response [40].

Minimum inhibitory concentration [MIC] was also calculated against both organisms using different concentration of samples. MIC values against $S$. typhi were found to be $1.16 \pm 0.15 \mathrm{~mm}$ for $10 \mu \mathrm{g} / \mathrm{ml}, 1.56 \pm 0.05 \mathrm{~mm}$ for $25 \mu \mathrm{g} /$ $\mathrm{ml}, 2.38 \pm 0.15 \mathrm{~mm}$ for $50 \mu \mathrm{g} / \mathrm{ml}, 3.2 \pm 0.20 \mathrm{~mm}$ for $100 \mu \mathrm{g} /$ $\mathrm{ml}$ for ZnONPs (GFM) and $0.96 \pm 0.14 \mathrm{~mm}$ for $10 \mu \mathrm{g} / \mathrm{ml}$, $1.63 \pm 0.07 \mathrm{~mm}$ for $25 \mu \mathrm{g} / \mathrm{ml}, 2.18 \pm 0.17 \mathrm{~mm}$ for $50 \mu \mathrm{g} /$ $\mathrm{ml}, 3.15 \pm \mathrm{mm}$ for $100 \mu \mathrm{g} / \mathrm{ml}$ for ZnONPs (SFM). MIC values against $B$. Subtilis were found to be $1.08 \pm 0.24 \mathrm{~mm}$ for $10 \mu \mathrm{g} / \mathrm{ml}, 2.01 \pm 0.22 \mathrm{~mm}$ for $25 \mu \mathrm{g} / \mathrm{ml}, 2.50 \pm 0.10 \mathrm{~mm}$ for $50 \mu \mathrm{g} / \mathrm{ml}, 2.98 \pm 0.22 \mathrm{~mm}$ for $100 \mu \mathrm{g} / \mathrm{ml}$ for ZnONPs (GFM) and $1.15 \pm 0.14 \mathrm{~mm}$ for $10 \mu \mathrm{g} / \mathrm{ml}, 1.5 \pm 0.07 \mathrm{~mm}$ for $25 \mu \mathrm{g} /$ $\mathrm{ml}, 2.18 \pm 0.17 \mathrm{~mm}$ for $50 \mu \mathrm{g} / \mathrm{ml}, 3.43 \pm 0.21 \mathrm{~mm}$ for $100 \mu \mathrm{g} /$ $\mathrm{ml}$ for ZnONPs (SFM).

By MIC we can notice a gradual increase in the zone of inhibition by increasing the concentration of nanoparticles which indicates the effect of nanoparticles on organisms.

We have observed that very low concentration of $\mathrm{ZnO}$ didn't show any activity against bacterial strains, which may be due to the presence of lesser zinc oxide nanoparticles present sometimes act as a nutrient for organisms. Antimicrobial activity is always higher above $5 \mu \mathrm{g} / \mathrm{ml}$ concentration [41].

Considering previous inhibition results obtained by Renata Dobruka et al., $31 \mathrm{~mm}$ for $1280 \mu \mathrm{g} / \mathrm{ml}$ of $\mathrm{ZnO}$ nanoparticle, Kumar et al., $35 \mathrm{~mm}$ for $1 \mathrm{mg} / \mathrm{ml}$ of $\mathrm{ZnO}$ nanoparticle and Kiranmayi et al., $4.5 \mathrm{~mm}$ for $100 \mu \mathrm{g} / \mathrm{ml}$ of $\mathrm{ZnO}$ nanoparticle [42-44], we can report our obtained results have shown prominent activity.

From MIC and ZOI we can clearly notice that $\mathrm{ZnO}$ synthesized using green synthesis always possess smaller particle size to have great antibacterial effects due to the larger surface area to volume ratio and surface reactivity. A number of studies have done on the considerable impact of particle size on the antibacterial activity, and the researchers found that controlling ZnO-NPs size was crucial to achieving a best bactericidal response, and ZnO-NPs with a smaller size (higher specific surface areas) showed highest antibacterial activity [45-47]. ZnONPs prepared from green synthesis method is more effective than another mode of preparation, which may be due to oxygen species released on the surface of $\mathrm{ZnO}$, which causes fatal damage to microorganisms [48]. The dissolution of ZnONPs into $\mathrm{Zn}^{2+}$ was reported as size dependent, and few studies suggested this dissolution of $\mathrm{Zn}^{2+}$ responsible for the toxicity of $\mathrm{ZnONPs}$. They react with hydrogen ions to produce molecules of $\mathrm{H}_{2} \mathrm{O}_{2}$. The generated $\mathrm{H}_{2} \mathrm{O}_{2}$ can penetrate the cell membrane and act lethally to microorganisms [49]. The generation of $\mathrm{H}_{2} \mathrm{O}_{2}$ depends strongly on the surface area of zin0c oxide nanoparticles, which 
Fig. 6 a and $\mathbf{b}$ Zone of inhibition of DMSO, ampicillin, and zinc oxide nanoparticles synthesized using goat faecal matter and sheep faecal matter against Salmonella typhimurium and Bacillus subtilis. $\mathrm{C}$ MIC of ampicillin against Salmonella typhimurium and Bacillus subtilis. d MIC of zinc oxide nanoparticles synthesized using goat faecal matter against Bacillus subtilis and Salmonella typhimurium. e MIC of zinc oxide nanoparticles synthesized using sheep faecal matter against Bacillus subtilis and Salmonella typhimurium a

b

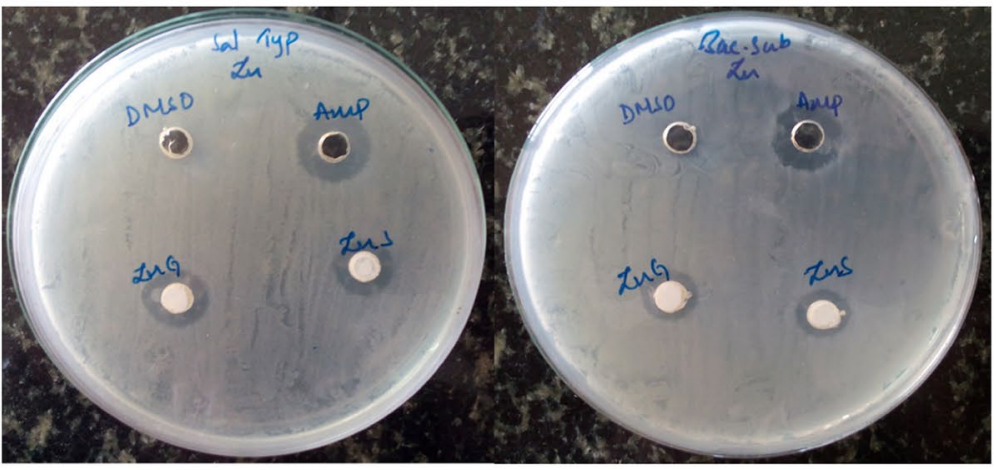

c

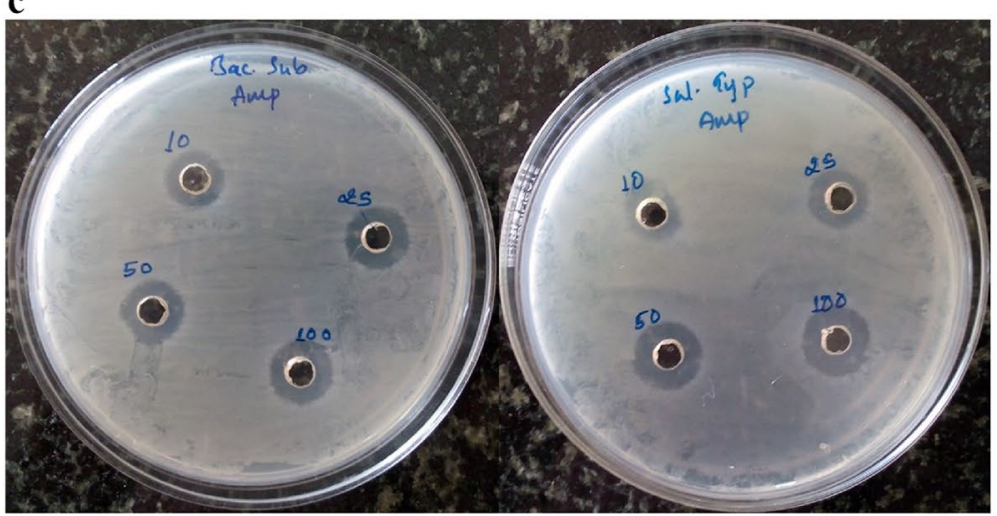

d

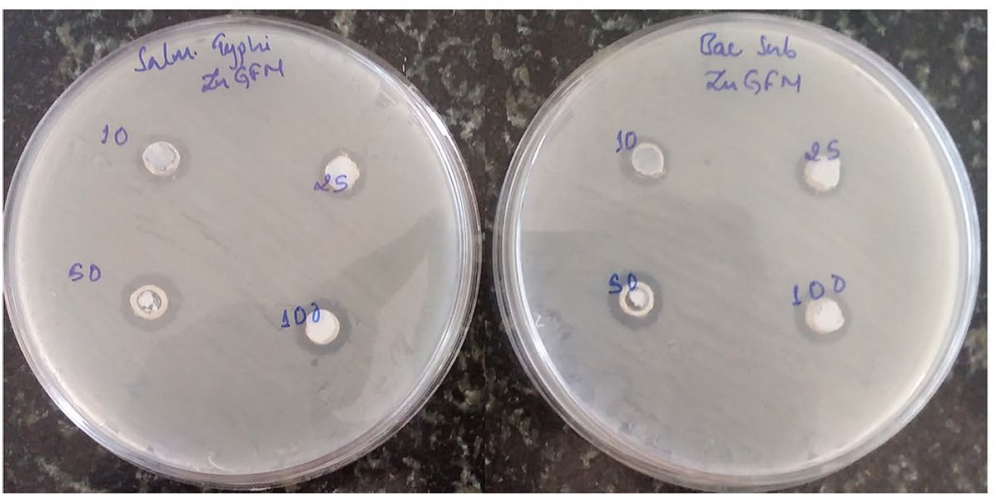

e

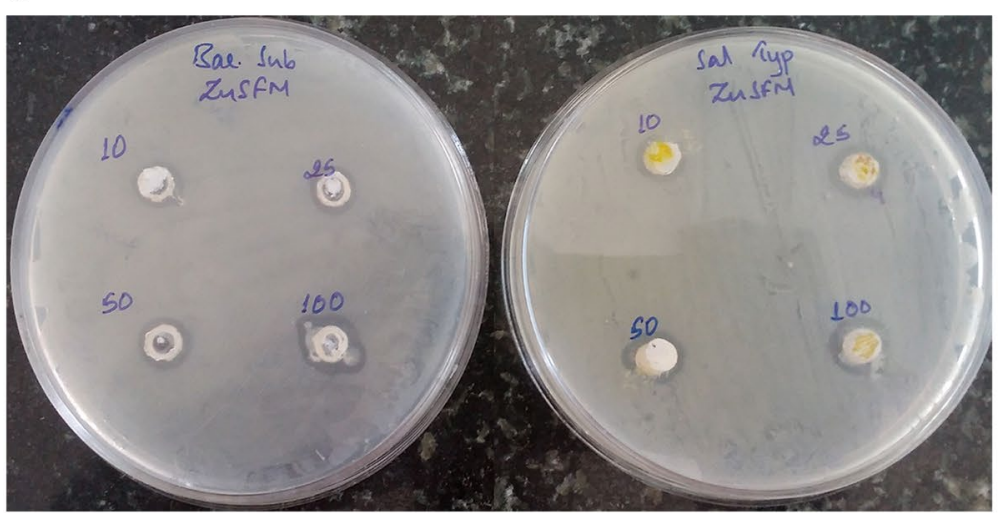


results in more oxygen species on the surface and the higher antibacterial activity of the smaller nanoparticles [50]. The effect of size and concentration was successfully analyzed by Padmavathy and Vijayaraghavan [51] who described the generation of $\mathrm{H}_{2} \mathrm{O}_{2}$, which depends mainly on the surface area of $\mathrm{ZnO}$. The larger the surface area and the higher concentration of oxygen species on the surface can obtain greater antibacterial activity by smaller particles, which was in contrast to that of Franklin et al. [52] who found no size-related effect. In general, a correspondence between nanoparticles size and bacteria appears to be required for the bioactivity of ZnONPs, as well the concentration (Fig. 6).

\section{Conclusion}

It is known that the green synthesis of ZnONPs is much safer and environmentally friendly as compared to chemical synthesis. In response to this assumption, this study demonstrates the use of agro waste materials goat and sheep faecal matter extract as a reducing agent. The synthesized ZnO nanoparticles were characterized by UV-Vis absorption spectroscopy, X-ray diffraction (XRD), Fourier transform infrared spectroscopy (FTIR), scanning electron microscopy (SEM) and Energy dispersive X-ray analysis (EDX). UV-visible Peaks at $352.67 \mathrm{~nm}$ and $356.60 \mathrm{~nm}$ indicate the formation of ZnONPs (GFM) and peaks at $352.60 \mathrm{~nm}$ and $353.67 \mathrm{~nm}$ for ZnONPs (SFM). By using XRD we have obtained average crystallite size of synthesized particles was calculated to be as $28.5 \mathrm{~nm}$ for ZnONPs (GFM) and $24.4 \mathrm{~nm}$ for ZnONPs (SFM). FTIR shows that peaks at $64.51 \mathrm{~cm}^{-1}$ for ZnONPs (GFM) and peaks at $433.79 \mathrm{~cm}^{-1}$ and $461.27 \mathrm{~cm}^{-1}$ for ZnONPs (SFM) were the characteristic absorptions of zinc oxide bond which confirms the formation of zinc oxide nanoparticles. By SEM characterizations, synthesized nanoparticles were observed to be spongy structure and flower-like structures, possess within the diameter of 40-120 nm for ZnONPs (GFM) and 60-130 nm for ZnONPs (SFM). EDS analysis shows the component mixtures of zinc oxide and other organic compounds. ZnONPs exhibits good antibacterial activity against both Bacillus Subtilis and Salmonella Typhimurium. MIC against both organisms was tested, at $10 \mu \mathrm{g} / \mathrm{ml}$ nanoparticles exhibits minimum activity. Zinc oxide nanoparticles prepared from green synthesis route are expected to have more extensive application in biotechnology, sensors, medical, catalysis, optical device, coatings and drug delivery. This is a highly effective rout of synthesis which involves reduction of chemicals and cost-effective which leads to digging out for further routes of environmental friendly nanoparticles.
Funding These authors declare that above-submitted work was not funded by any governmental or private funding source nor supported by any financial projects.

\section{Compliance with ethical standards}

Conflict of interest The authors declare that they have no conflict of interest.

Open Access This article is distributed under the terms of the Creative Commons Attribution 4.0 International License (http://creativeco mmons.org/licenses/by/4.0/), which permits unrestricted use, distribution, and reproduction in any medium, provided you give appropriate credit to the original author(s) and the source, provide a link to the Creative Commons license, and indicate if changes were made.

\section{References}

1. Huang J, Lin L, Sun D, Chen H, Yang D, Li Q (2015) Bio-inspired synthesis of metal nanomaterials and applications. Chem Soc Rev 44(17):6330-6374

2. Hakim LF, Portman JL, Casper MD, Weimer AW (2005) Aggregation behavior of nanoparticles in fluidized beds. Powder Technol 160(3):149-160

3. Mukherjee $P, A$ hmad $A$, Mandal $D$, Senapati $S$, Sainkar SR, Khan MI, Parishcha R, Ajaykumar PV, Alam M, Kumar R, Sastry M (2001) Fungus-mediated synthesis of silver nanoparticles and their immobilization in the mycelial matrix: a novel biological approach to nanoparticle synthesis. Nano Lett 1(10):515-519

4. Tripp SL, Pusztay SV, Ribbe AE, Wei A (2002) Self-assembly of cobalt nanoparticle rings. J Am Chem Soc 124(27):7914-7915

5. Kumar B, Smita K, Cumbal L, Debut A (2017) Sacha inchi (Plukenetia volubilis L.) shell biomass for synthesis of silver nanocatalyst. J Saudi Chem Soc 21(Sup. 1):s293-s298. https://doi. org/10.1016/j.jscs.2014.03.005

6. Haverkamp RG, Marshall AT (2009) The mechanism of metal nanoparticle formation in plants: limits on accumulation. J Nanoparticle Res 11:1453-1463. https://doi.org/10.1007/s1105 1-008-9533-6

7. Kumar B, Smita K, Cumbal L, Debut A (2014) Biogenic synthesis of iron oxide nanoparticles for 2-arylbenzimidazole fabrication. J Saudi Chem Soc 18:364-369. https://doi.org/10.1016/j. jscs.2014.01.003

8. Saifuddin N, Wong CW, Nur Yasumira AA (2009) Rapid biosynthesis of silver nanoparticles using culture supernatant of bacteria with microwave irradiation. E-J Chem 6:61-70. https://doi. org/10.1155/2009/734264

9. Baliga MS, Kurian PJ (2012) Ixora coccinea Linn.: traditional uses, phytochemistry and pharmacology. Chin J Integr Med 18:72-79. https://doi.org/10.1007/s11655-011-0881-3

10. Deepali Sharma JR, Kaith BS, Kaur Mohinder, Sharma Sapna (2010) Synthsis of ZnO nanoparticals and study of their antibacterial and antifungal properties. Thin Solid Films 519:1224-1229

11. Hussein J, El-Banna M, RazikTA, El-Nagga ME (2017) Biocompatible zinc oxide nanocrystals stabilized via hydroxyethyl cellulose for mitigation of diabetic complications. Int J Biol Macromol. https://doi.org/10.1016/j.ijbiomac.2017.09.056

12. Wang L, Kang Y, Liu X, Zhang S, Huang W, Wang S (2012) ZnO nanorod gas sensor for ethanol detection. Sens Actuators B: Chem 162:237-243. https://doi.org/10.1016/j.snb.2011.12.073

13. Cross SE, Innes B, Roberts MS, Tsuzuki T, Robertson TA, McCormick $P$ (2007) Human skin penetration of sunscreen nanoparticles: in vitro assessment of a novel micronized zinc oxide 
formulation. Skin Pharmacol Physiol 20:148-154. https://doi. org/10.1159/000098701

14. Zhou J, Xua N, Wang ZL (2006) Dissolving behavior and stability of $\mathrm{ZnO}$ wires in biofluids: a study on biodegradability and biocompatibility of ZnO nanostructures. Adv Mater 18:2432-2435. https://doi.org/10.1002/adma.200600200

15. Rasmussen JW, Martinez E, Louka P, Wingett DG (2010) Zinc oxide nanoparticles for selective destruction of tumor cells and potential for drug delivery applications. Exp Opin Drug Deliv 7:1063-1077. https://doi.org/10.1517/17425247.2010.502560

16. Shaheen TI, El-Naggar ME, Abdelgawad AM, Hebeish A (2015) Durable antibacterial and UV protections of in situ synthesized zinc oxide nanoparticles onto cotton fabrics. Int J Biol Macromol. https://doi.org/10.1016/j.ijbiomac.2015.11.003

17. Raliya R, Tarafdar JC (2013) ZnO nanoparticle biosynthesis and its effect on phosphorous-mobilizing enzyme secretion and gum contents in clusterbean (Cyamopsis tetragonoloba L.). Agric Res 2(1):48-57. https://doi.org/10.1007/s40003-012-0049-z

18. Kadhim QA, Alwan RM, Ali RA, Jassim AN (2016) Synthesis of zinc oxide/polystyrene nanocoposite films and study of antibacterial activity against escherichia coli and Staphylococcus aureus. Nanosci Nanotechnol 6(1):1-5. https://doi.org/10.5923/j. nn.20160601.01

19. Jamdagni $P$, Khatri $P$, Rana JS (2016) Green synthesis of zinc oxide nanoparticles using flower extract of Nyctanthes arbor-tristis and their antifungal activity. J King Saud Univ Sci. https://doi. org/10.1016/j.jksus.2016.10.002

20. El-Naggar ME, Shaarawy S, Hebeish AA (2017) Multifunctional properties of cotton fabrics coated with in situ synthesis of Zinc oxide nanoparticles capped with date seed extract. Carbohydr Polym. https://doi.org/10.1016/j.carbpol.2017.10.074

21. Chena C, Yu B, Liu P, Liu JF, Wang L (2011) Investigation of nanosized $\mathrm{ZnO}$ particles fabricated by various synthesis routes. J Ceram Process Res 12:420-425

22. Pung Swee-Yong, Lee Wen-Pie, Aziz Azizan (2012) Kinetic study of organic dye degradation using $\mathrm{ZnO}$ particles with different morphologies as a photocatalyst. Inte J Inorg Chem 2012:1-9

23. Culity BD (1987) Elements of X-ray diffraction, 2nd edn. AddisonWesley, Bostaon

24. Sathyavathi R, Krishna MB, Rao SV, Saritha R, Rao DN (2010) Biosynthesis of silver nanoparticles using Coriandrum Sativum leaf extract and their application in nonlinear optics. Adv Sci Lett 3:01-06

25. Oancea A, Grasset O, Le Menn E, Bollengier O, Bezacier L, Le Mouélic S, Tobie G (2012) Laboratory infrared reflection spectrum of carbon dioxide clathrate hydrates for astrophysical remote sensing applications. Icarus. https://doi.org/10.1016/j. icarus.2012.09.020

26. Renuga Devi TS, Gayathri S (2010) FTIR and FT-Raman spectral analysis of paclitaxel drugs. Int J Pharm Sci Rev Res 2:106-110

27. Singh AK, Talat M, Singh DP, Srivastava ON (2010) Biosynthesis of gold and silver nanoparticles by natural precursor clove and their functionalization with amine group. J Nanoparticle Res 12:1667-1675

28. Saikia BJ, Parthasarathy G, Sarmah NC (2009) Fourier transform infrared spectroscopic characterization of dergaon $\mathrm{H} 5$ chondrite: evidence of aliphatic organic compound. Nat Sci 7(5):45

29. Kwon YJ, Kim KH, Lim CS, Shim KB (2002) Characterization of ZnO nanopowders synthesized by the polymerized complex method via an organochemical route. J Ceram Proc Res 3:146-149

30. Silva RF, Zaniquelli MED (2002) Morphology of nanometric size particulate aluminium doped zinc oxide films. Colliod Surf Physicochem Eng Aspect 198-200:551-558

31. Li H, Wang J, Liu H (2004) Sol-gel preparation of transparent zinc oxide films with highly preferential crystal orientation. Vacuum 77(1):57-62p
32. Sangeetha G, Rajeshwari S, Venckatesh R (2011) Green synthesis of Zinc oxide nanoparticles by aloe barbadensis miller leaf extract, structure and optical properties. Mater Res Bull 46(12):2560-2566

33. Gnanasangeetha D, Sarala Thambavani D (2013) One pot synthesis of zinc oxide nanoparticles via chemical and green method. Res J Mater Sci 1(7):1-8

34. Agarwal H, Kumar SV, Rajeshkumar S (2017) A review on green synthesis of zinc oxide nanoparticles-an eco-friendly approach. Resour-Eff Technol. https://doi.org/10.1016/j.reffi t.2017.03.002

35. Beveridge TJ, Murray RJ (1980) Sites of metal deposition in the cell wall of Bacillus subtilis. J Bacteriol 141:876-887

36. Perez C, Pauli M, Bazerque $P$ (1990) An antibiotic assay by agar well diffusion method. Acta Biol Med Exp 15:113-115

37. Kim JH, Cho H, Ryu SE, Choi MU (2000) Effects of metal ions on the activity of protein tyrosine phosphatase VHR: highly potent and reversible oxidative inactivation by $\mathrm{Cu} 2+$ ion. Arch Biochem Biophys 382:72-80

38. Stohs SJ, Bagchi D (1995) Oxidative mechanisms in the toxicity of metal ions. Free Radic Bio Med 18:321-336

39. El-Naggar Mehrez E, Shaarawy S, Hebeish AA (2017) Bactericidal finishing of loomstate, scoured and bleached cotton fibres via sustainable in situ synthesis of silver nanoparticles. Int J Biol Macromol. https://doi.org/10.1016/j.ijbiomac.2017.08.127

40. Tawale JS, Dey KK, Pasricha R, Sood KN, Srivastava AK (2010) Synthesis and characterization of $\mathrm{ZnO}$ nanostructures for optical and antibacterial applications. Thin Solid Films 519(3):1244-1247

41. Sawai J (2003) Quantitative evaluation of antibacterial activities of metallic oxide powders ( $\mathrm{ZnO}, \mathrm{MgO}$ and $\mathrm{CaO}$ ) by conductimetric assay. J Microbiol Methods 54:177-182

42. Senthilkumar SR, Sivakumar T (2014) Green tea (Camellia sinensis) mediated synthesis of zinc oxide $(\mathrm{ZnO})$ Nanoparticles and studies on their antimicrobial activities. Int J Pharm Pharm Sci 6(6):461-465

43. Dobrucka R, Dlugaszewska J, Kaczmarek M (2018) Cytotoxic and antimicrobial effects of biosynthesized $\mathrm{ZnO}$ nanoparticles using of Chelidonium majus extract. Biomed Microdevices. https://doi. org/10.1007/s10544-017-0233-9,20:5

44. Kumar G, Badoni PP (2017) Antimicrobial activity of Rhusparviflora Roxb.: leaves extract mediated synthesized $\mathrm{ZnO}$ nanoparticles. Int J Chem Tech Res 10(7):377-381

45. Ravi Chandrika K, Kiranmayi P, Ravikumar RVSSN (2012) Synthesis, characterization and antibacterial activity of $\mathrm{ZnO}$ nanoparticles. Int J Pharm Sci 4(4):336-338

46. Yamamoto $O(2001)$ Influence of particle size on the antibacterial activity of zinc oxide. Int J Inorg Mater 3(7):643-646. https ://doi.org/10.1016/S1466-6049(01)00197-0

47. Brunner TJ, Wick $P$, Manser $P$, Spohn $P$, Grass RN, Limbach LK, Bruinink A, Stark WJ (2006) In vitro cytotoxicity of oxide nanoparticles: comparison to asbestos, silica, and the effect of particle solubility. Environ Sci Technol 40(14):4374-4381. https://doi. org/10.1021/es052069i

48. Sunanda K, Kikuchi Y, Hashimoto K, Fujishima A (1998) Bactericidal and detoxification effects of $\mathrm{TiO}_{2}$ thin film photocatalysts. Environ Sci Technol 32(1998):726-728

49. Fang $M, C h e n ~ J H, X u ~ X L$, Yang $P H$, Hildebrand HF (2006) Antibacterial activities of inorganic agents on six bacteria associated with oral infections by two susceptibility tests. Int J Antimicrob Agents 27:513-517

50. Yamamoto O, Komatsu M, Sawai J, Nakagawa Z (2008) Effect of lattice constant of zinc oxide on antibacterial characteristics. J Mater Sci Mater Med 19:1407-1412

51. Padmavathy N, Vijayaraghavan R (2008) Enhanced bioactivity of $\mathrm{ZnO}$ nanoparticles-an antimicrobial study. Sci 
Technol Adv Mater 9(3):035004. https://doi.org/10.1088/14686996/9/3/035004

52. Franklin NM, Rogers NJ, Apte SC, Batley GE, Gadd G, Casey PS (2007) Comparative Toxicity of Nanoparticulate ZnO, Bulk ZnO, and $\mathrm{ZnCl}_{2}$ to a freshwater microalga (Pseudokirchneriella subcapitata): the importance of particle solubility. Environ Sci Technol 41(24):8484-8490. https://doi.org/10.1021/es071445r

\section{SN Applied Sciences}

a SPRINGER NATURE journal 